\title{
RECOVERY OF COPPER AND SILVER OF PRINTED CIRCUIT BOARDS FROM OBSOLETE COMPUTERS BY ONE-STEP ACID LEACHING
}

\author{
Lidiane Maria de Andrade ${ }^{1, \star}$, Mariana Alves de Carvalho ${ }^{1}$, Marcos Paulo Kohler Caldas ${ }^{2}$, \\ Denise Crocce Romano Espinosa ${ }^{1}$ and Jorge Alberto Soares Tenório ${ }^{1}$ \\ ${ }^{1}$ Laboratory of Recycling, Waste Treatment and Extraction (LAREX), Department of Chemical Engineering of the Polytechnic School, \\ University of São Paulo, CP 05505-080, São Paulo, SP, Brazil \\ ${ }^{2}$ Federal Institute of Education, Science and Technology of Espirito Santo, Serra Campus, CP 29173-087, Serra, ES, Brazil
}

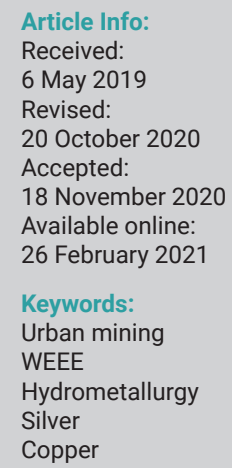

\begin{abstract}
Over the years, the generation of Waste Electric and Electronic Equipment has been significantly increased, which leads to environmental and economic concerns. Thus, it is fundamental to develop treatment methods for these residues. Printed Circuit Boards are essential components of electronic equipments. In this sense, printed circuit boards are composed of remarkable metals, in particular, copper and silver at high and low concentrations, respectively. These metals can be recovered by the hydrometallurgical process followed by a chemical purification step. Therefore, the aim of this study was to leach silver and copper from two different printed circuit boards (memory board and motherboard) from obsolete computers by hydrometallurgical route based on only one-stage leaching in oxidant media. When compared to the motherboard, a higher recovery rate of Ag was obtained from memory boards $83 \%$ and $33 \%$, respectively. Whereas, similar recovery rates of copper were observed for memory board and motherboard, $48 \%$ and $46 \%$, respectively.
\end{abstract}

\section{INTRODUCTION}

Over the past 20 years, there has been a massive increase in the production of electric and electronic equipments (EEEs). Simultaneously, the EEE have shorter and shorter life cycles. Consequently, there is a substantial and alarming generation of the waste electric and electronic equipments (WEEEs) (GHOSH et al., 2015).

Regarding WEEEs, its heterogeneous composition (ceramic, polymeric materials, and also a considerable amount of metals), hinders the control and development of efficient treatment methods. Thus, it is essential to do research on alternatives for the treatment and correct disposal of WEEE (Kumar et al., 2017; Shokri et al., 2017). In this sense, the European Parliament has published some instructions on the management of WEEEs (Official Journal of the European Union, 2003a, Official Journal Of European Union, 2003b).

Printed Circuit Boards (PCBs) are essential components of WEEEs, that is, PCBs represent a significant volume of WEEEs. PCBs are quite heterogenic materials, composed of different metals, for instance, $\mathrm{Al}, \mathrm{Cu}, \mathrm{Fe}, \mathrm{Ni}, \mathrm{Sn}$, and $\mathrm{Zn}$, and also high added-value metals as $\mathrm{Au}, \mathrm{Ag}$, and $\mathrm{Pt}$. It is worth noting that toxic metals as $\mathrm{Cd}, \mathrm{Hg}$, and $\mathrm{Pb}$ can also be found in PCBs (Cui and Anderson, 2006).
Thus, taking into account the volume of WEEEs and their composition, in particular high added-value metals, it is a quite interesting strategy to recovery some metals - urban mining concept (Diaz et al., 2015).

Due to its remarkable properties such as high mechanical and corrosion resistance, good conductor of electricity and heat copper is widely used in industrial processes, including PCBs, in which can reach reach 20 wt\%. In September of 2020, the market value of copper was US\$ 6,788.5 per ton (Xu et al., 2016; LME, 2020a). In addition, according to the European Union - Restriction of Hazardous Substances Directive (RoHS), which is related to the restriction in the use of certain hazardous substances in electrical and electronic equipment, the production of traditional eletronic boards should be changed by lead free eletronic boards, in which $\mathrm{Pb}$ is replaced by $\mathrm{Ag}$ without any performance damage due to the great properties of the precious metal. Nevertheless, $\mathrm{Ag}$ is a high added-value metal. In September of 2020, the market value of silver reached US\$ $911,311.59$ per ton. It means that even in lower concentrations in comparison to another metal, the $\mathrm{Ag}$ market value, 134 times higher than $\mathrm{Cu}$, turns it into a really important metal in terms of the intrinsic value of the board (Cayumil et al., 2016; KITCO, 2018; LME, 2020b).

The metal recovery from PCBs can be carried out by hy-
Detritus / Volume 14 - 2021 / pages 86-91 https://doi.org/10.31025/2611-4135/2021.14056 (C) 2019 Cisa Publisher. Open access article under CC BY-NC-ND license 
drometallurgically (Cui and Anderson, 2016), pyrometallurgically (Bidini et al., 2015) or biohydrometallurgically (Ilyas et al., 2010). The hydrometallurgical process is based on the metal leaching using acid or alkali molecules, followed by chemical process that recover the metals of interest $(\mathrm{Xu}$ et al., 2016; Neto et al., 2016; Kumar et al., 2015; Choubey et al., 2015). In this sense, a new two-stage hydrometallurgical route was described by Silvas et al. (2015), the first stage is acidic medium composed of sulfuric acid, whereas the second stage is an oxidant solution composed of sulfuric acid and hydrogen peroxide. The authors extracted $100 \%$ of copper from PCBs from printers.

Therefore, the aim of this study was to leach silver and copper from two different PCBs (memory board and motherboard) from obsolete computers by hydrometallurgical route based on only one-stage leaching in oxidant media.

\section{MATERIAL AND METHODS}

\subsection{Physical-chemical characterization of memory board and motherboard}

Two different lead-free boards from obsolete computers were used (motherboard and memory board). The boards were obtained from Centro de Descarte e Reúso de Resíduos de Informática da Universidade de São Paulo (CEDIR-USP). The physical processing included: manual disassembling, comminution, and quartering. Approximately 1 $\mathrm{kg}$ of each board was comminuted, which corresponds to 5 motherboards and 20 memory boards. Then, the motherboards and memory boards without external and removable polymeric components were physical-chemical characterized (as below).

\subsubsection{Physical processing}

The comminution was performed using two mills in sequence: a knife mill (RONE FA2305) with a $9 \mathrm{~mm}$ grid, and a hammer mill (ASTECMA MDM 18/18) with a $2 \mathrm{~mm}$ grid. The resulting material was quartered in a Johnes quarter to separate homogeneously the samples into small fractions, of $20 \pm 5 \mathrm{~g}$.

\subsubsection{Aqua regia digestion and chemical analysis}

$5 \mathrm{~g}$ of the sample was submitted of aqua regia digestion, with a solid-liquid ratio of 1:20 - a volume of $100 \mathrm{~mL}$ of aqua regia was used for the solubilization of the metals. The digestion occurred at room temperature and atmospheric pressure for 24 hours. After the reaction, the liquor was filtered using a quantitative filter paper (porosity of $0.75 \mu \mathrm{m}$ ). Then, $10 \mathrm{~mL}$ of permeate was used to quantify silver and copper by ICP-OES.

\subsubsection{Loss on ignition test}

The residue after aqua regia digestion was filtered using a quantitative filter paper (porosity of $0.75 \mu \mathrm{m}$ ). Then, the solid fraction was washed using deionized water and oven-dried at $60 \pm 5^{\circ} \mathrm{C}$ for 24 hours. The material was transferred to a porcelain crucible and lead to a muffle with a heating rate of $10^{\circ} \mathrm{C} / \mathrm{min}$ until it reaches $800^{\circ} \mathrm{C}$ and then maintained for 1 hour. After turned off, the muffle cooled to room temperature and then weighed again. The sam- ple was maintained in a desiccator for 24 hours and after weighed again to verify the sample weight constant.

\subsection{Hydrometallurgical Processing}

The one-stage acid leaching in oxidant media were conducted for both boards. The leaching agent was sulfuric acid $\left(\mathrm{H}_{2} \mathrm{SO}_{4}\right) 2 \mathrm{M}$. $100 \mathrm{~g}$ of boards were solubilized in 2,000 $\mathrm{mL}$ of acid under the following conditions:

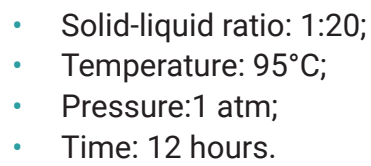

Additionally, $15 \mathrm{~mL}$ of hydrogen peroxide $\left(\mathrm{H}_{2} \mathrm{O}_{2}\right) 35 \%$ (oxidant agent) was added every 15 minutes for 12 hours. $10 \mathrm{~mL}$ sampling was carried out every hour. Then, the liquor was colled at room temperature and filtered using a quantitative filter paper (porosity of $0.75 \mu \mathrm{m}$ ). The permeate was used to quantify silver and copper by ICP-OES.

\section{RESULTS AND DISCUSSION}

\subsection{Physical-chemical characterization of memory board and motherboard}

\subsubsection{Aqua regia digestion and chemical analysis}

After the physical processing and aqua regia digestion, the analysis of ICP-OES data showed that both memory board and motherboard have several metals such as, Al, $\mathrm{Au}, \mathrm{Cu}, \mathrm{Fe}, \mathrm{Ni}, \mathrm{Sn}$, and Zn (Table 1).

When compared to memory board, motherboard showed higher metal mass fraction $35.510 \%$ and $18.910 \%$, respectively (Table 1$)$. These results are aligned to Gosh et al. (2015) and Kaya (2016).

Regarding copper in terms of mass fraction, it was observed similar concentrations for both motherboard and the memory board. However, in terms of metal mass fraction, copper represents $55.3 \%$ for motherboard and $73.1 \%$ for memory board. In other words, the highest metallic concentration is related to copper ( $>50 \%)$. Thus, copper is the most promising metal that can be recovered from motherboard and memory board, whereas for silver, lower mass fraction was observed ( $\approx 340 \times$ than copper). Nevertheless, a similar mass fraction was observed for both

TABLE 1: Metal mass fraction of motherboard and memory board.

\begin{tabular}{|c|c|c|}
\hline \multirow{2}{*}{ Metal } & \multicolumn{2}{|c|}{ Mass fraction } \\
\hline & Motherboard & Memory board \\
\hline $\mathrm{Ag}$ & $0.045 \%$ & $0.053 \%$ \\
\hline $\mathrm{Al}$ & $2.660 \%$ & $1.403 \%$ \\
\hline $\mathrm{Au}$ & $0.002 \%$ & $0.069 \%$ \\
\hline $\mathrm{Cu}$ & $19.650 \%$ & $13.830 \%$ \\
\hline $\mathrm{Fe}$ & $8.340 \%$ & $1.470 \%$ \\
\hline $\mathrm{Ni}$ & $0.270 \%$ & $0.320 \%$ \\
\hline Sn & $1.990 \%$ & $1.700 \%$ \\
\hline $\mathrm{Zn}$ & $2.550 \%$ & $0.043 \%$ \\
\hline Total & $35.510 \%$ & $18.910 \%$ \\
\hline
\end{tabular}


motherboard and the memory board. In addition, in terms of metal mass fraction, silver corresponds to $0.1 \%$ for the motherboard and $0.2 \%$ for the memory board. Thus, on the one hand, copper is the most abundant metals in both the motherboard and the memory board, on the other hand, even at low mass fraction $(\approx 0.05 \%)$, silver can be recovered from PCBs due to its high added-value.

\subsubsection{Loss on ignition test}

Based on the stoichiometry, $\mathrm{H}+$ in excess (around 10 times) dissolve all metals present in the PCBs and strongly acid $\mathrm{pH}$ conditions are suitable to maintain the formed salts in solution.

Thus, the remaining material (after aqua regia digestion) is composed of only ceramic and polymeric compounds. In this sense, polymers are thermal degradable. Thus, the loss on ignition test indicates the mass of polymeric fraction (volatile) by gravimetry method, in which the non-volatile mass fraction corresponds to the ceramic compounds of the boards (llyas et al., 2007).

Based on loss on ignition test and aqua regia digestion data, the material compositions of motherboard and memory board are shown in Figure 1.

For both memory board and motherboard, ceramic compounds were majority $48.4 \%$ and $38.7 \%$, respectively. Very likely, due to the fiberglass that is widely applied for other PCB components. These results are aligned to Zhou and Qiu (2010) that described the composition of PCB wastes $\approx 28 \%$ of metals and $72 \%$ of non-metals such as plastic, ceramic, etc.

\subsection{Hydrometallurgical processing}

The chemical analysis by ICP-OES of the liquor obtained at the end of the acid leaching in the oxidant media process allowed to calculate the percentage of extraction of each metal on the boards, based on characterization results showed in Table 1. This analysis resulted in Table 2.

A previous study (Silvas et al., 2015) showed that the leaching of both $\mathrm{Cu}$ and $\mathrm{Ag}$ from PCB from printers can be carried out in acid solutions and oxidant medium.

\subsubsection{Motherboard}

The leaching curves of $\mathrm{Ag}$ and $\mathrm{Cu}$ for motherboard and memory board are shown in Figures 2 and 3.
TABLE 2: Percentage of extraction of metals for the motherboard and the memory board.

\begin{tabular}{c|cc}
\multirow{2}{*}{ Metal } & \multicolumn{2}{c}{ Extraction } \\
\cline { 2 - 3 } & Motherboard & Memory board \\
\hline $\mathrm{Al}$ & $33 \%$ & $83 \%$ \\
\hline $\mathrm{Au}$ & $99 \%$ & $100 \%$ \\
\hline $\mathrm{Cu}$ & $0 \%$ & $0 \%$ \\
\hline $\mathrm{Fe}$ & $48 \%$ & $46 \%$ \\
\hline $\mathrm{Ni}$ & $100 \%$ & $81 \%$ \\
\hline $\mathrm{Sn}$ & $89 \%$ & $83 \%$ \\
\hline $\mathrm{Zn}$ & $31 \%$ & $15 \%$ \\
\hline & $88 \%$ & $100 \%$ \\
\hline
\end{tabular}

Considering the initial mass (100 g) and the concentration of each metal obtained by chemical characterization for the motherboard, the maximum mass that could be extracted was $0.045 \mathrm{~g}$ and $19.65 \mathrm{~g}$ for silver and copper, respectively. However, the one-step acid leaching reached $33 \%$ and $48 \%$, respectively for silver (Figure 2) and copper (Figure 3), which corresponds to $0.015 \mathrm{~g}$ of $\mathrm{Ag}$ and 9.432 $\mathrm{g}$ of copper. Thus, the other metals in the liquor such as $\mathrm{Ni}, \mathrm{Sn}$, and $\mathrm{Zn}$ that form stable alloys in solution, can negatively affect the total leaching of $\mathrm{Ag}$ and $\mathrm{Cu}$ (SILVAS et al., 2015).

The high added-value metals need a quite high ORP for high yields of hydrometallurgical recovery. In addition, partial purification, mainly non-added value metals, can significantly enhance the yields of high added-value metals (Žiūkaitè et al., 2017). It was observed that the leaching of $\mathrm{Ag}$ only started began after 7 hours (Figure 2), very likely due to the acid reaction with other metals, such as copper. As far as the copper is being leached, the remained acid can start to leach the precious metals increasing the concentration through the process since the Ag leaching is generally performed after removal of Cu (GURUNG et al., 2013).

Thus, the partial purification of other metals, high ORP, favorable $\mathrm{pH}$ and at least 10 hours of leaching process could enhance the copper and silver yields of leaching from motherboard and memory board.

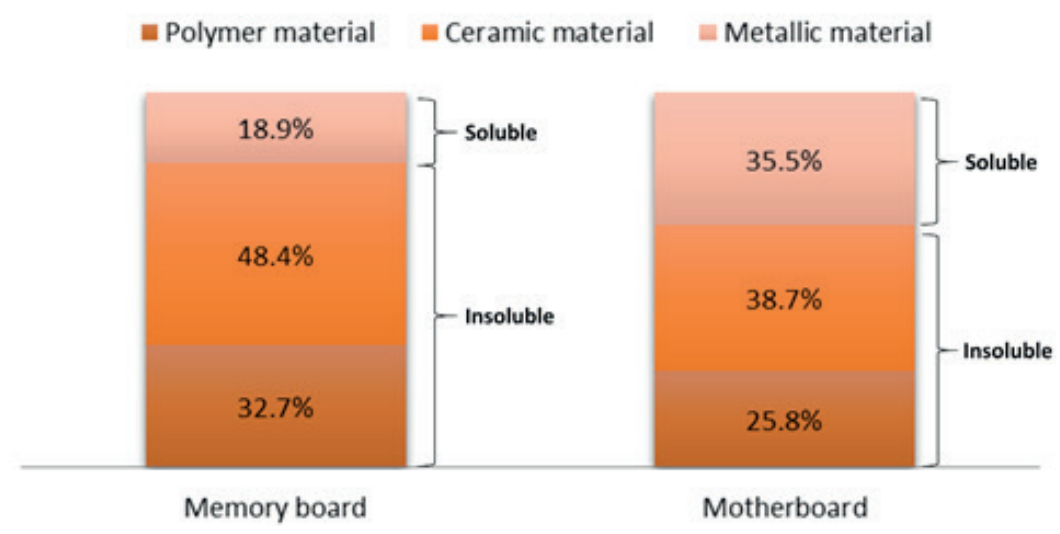

FIGURE 1: Material compositions of motherboard and memory board. 


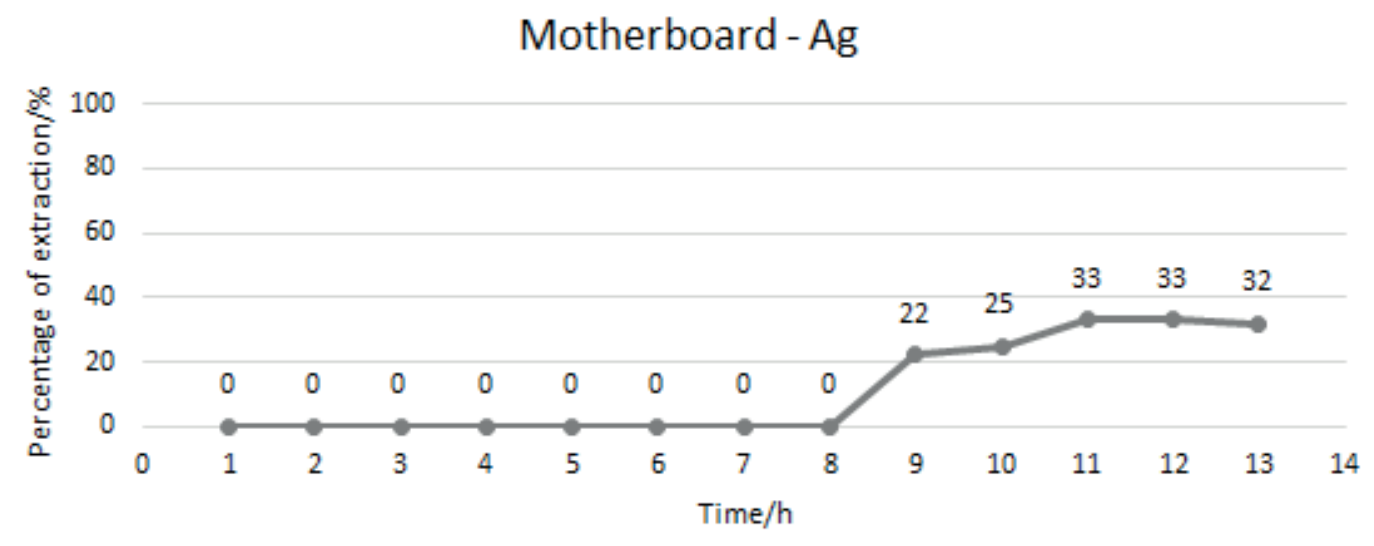

FIGURE 2: Leaching curve of Ag for the motherboard with the percentage of extraction over time.

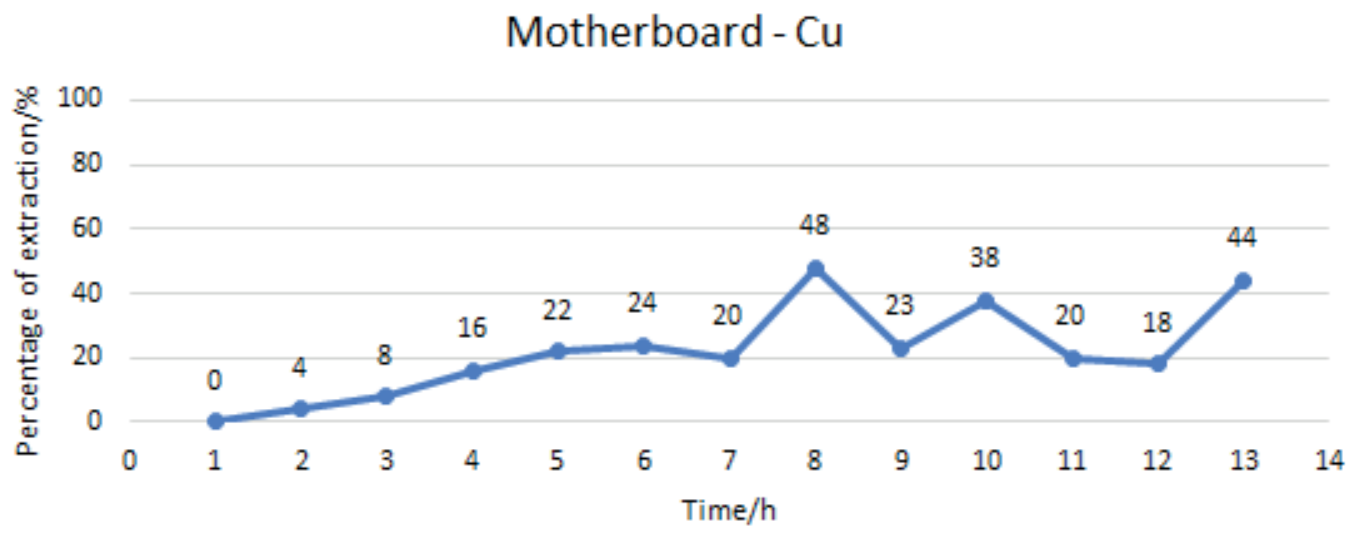

FIGURE 3: Leaching curve of Cu for the motherboard with the percentage of extraction over time.

\subsubsection{Memory Board}

The leaching curves of $\mathrm{Ag}$ and $\mathrm{Cu}$ for the memory board are shown in Figures 4 and 5, respectively. Taking into account the initial mass of the PCBs $(100 \mathrm{~g})$ and the concentration of each metal obtained by chemical characterization, the maximum mass that could be extracted from the memory board was $0.053 \mathrm{~g}$ fo $\mathrm{Ag}$ and $13.83 \mathrm{~g}$ for $\mathrm{Cu}$ (Table 1). The one-step acid leaching of $\mathrm{Ag}$ and $\mathrm{Cu}$ reached, respectively, $83 \%$ and $46 \%$, which corresponds to a mass of $0.044 \mathrm{~g}$ of $\mathrm{Ag}$ and $6.362 \mathrm{~g}$ of $\mathrm{Cu}$, respectively.

The increased percentage of extraction over time for both metals, $\mathrm{Ag}$ and $\mathrm{Cu}$, was also observed for the memory board. However, similarly to the observed for motherboard leaching, the remotion of impurities, longer leaching reaction time (at least 7 hours) combined with the ORP and $\mathrm{pH}$ optimum conditions could further improve the process maximizing the simultaneous extraction for $\mathrm{Cu}$ and $\mathrm{Ag}$.

Additionally, the high yield of $\mathrm{Ag}$ extraction can be related to the metal mass fraction for both motherboard and memory board, and the solid-liquid ratio used for the acid leaching process. Whereas on the motherboard the metallic fraction is $35.5 \%$ and the Ag represents $0.1 \%$ of this amount, on the memory board $\mathrm{Ag}$ represents $0.2 \%$ of a smaller metallic fraction, $18.9 \%$. It means that, on the memory board, a higher amount of acid was available to interact with the metals and promote the leaching, there- fore improving the efficiency of the hydrometallurgical process.

\section{CONCLUSIONS}

The hydrometallurgical process of one-stage acid leaching in oxidant media allowed to recover $\mathrm{Ag}$ and $\mathrm{Cu}$, the two most expressive metals in terms of intrinsic value and amount respectively, from PCBs from obsolete computers (motherboard and memory board). Both metals Ag and $\mathrm{Cu}$ were recovered by one-stage acid leaching in oxidant medium. When compared to motherboard, the memory board reached higher recovery of $\mathrm{Ag}, 83 \%$ after 12 hours. However, the partial purification of other metals, high ORP, favorable $\mathrm{pH}$ and at least 10 hours of leaching process could enhance the copper and silver yields of leaching from motherboard and memory board. Regarding Cu recovery, it was quite similar to both memory board and motherboard, since it reached $48 \%$ and $46 \%$, respectively. Therefore, the one-stage leaching is a promising strategy to recover metals from PCBs from obsolete computers.

\section{ACKNOWLEDGEMENTS}

The authors gratefully acknowledge the financial support given by Conselho Nacional de Desenvolvimento Científico e Tecnológico (CNPq) (131479/2017-2) and 


\section{Memory board - Ag}

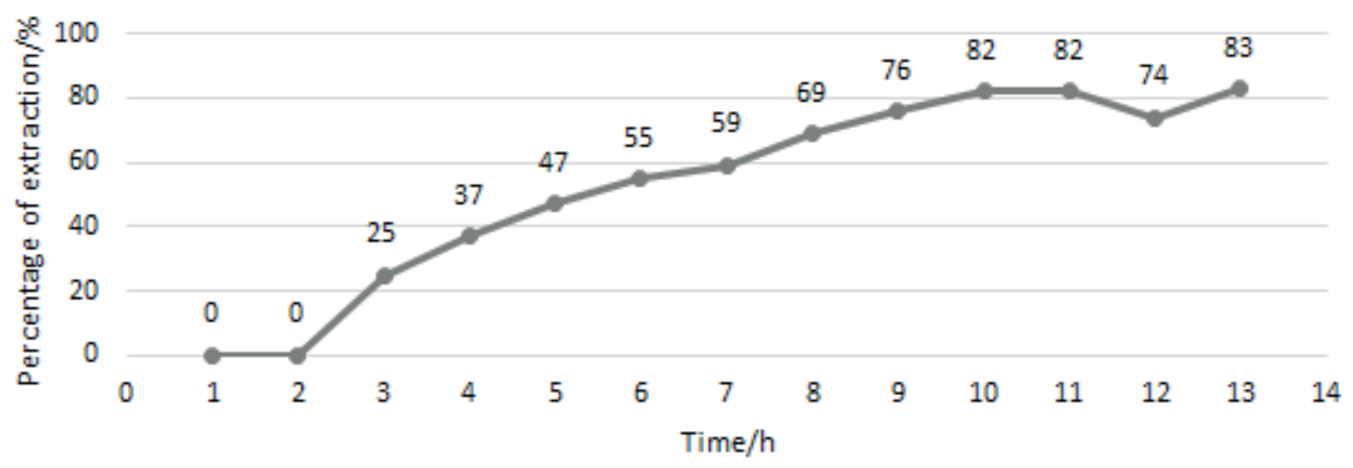

FIGURE 4: Leaching curve of Ag for the memory board with the percentage of extraction over time.

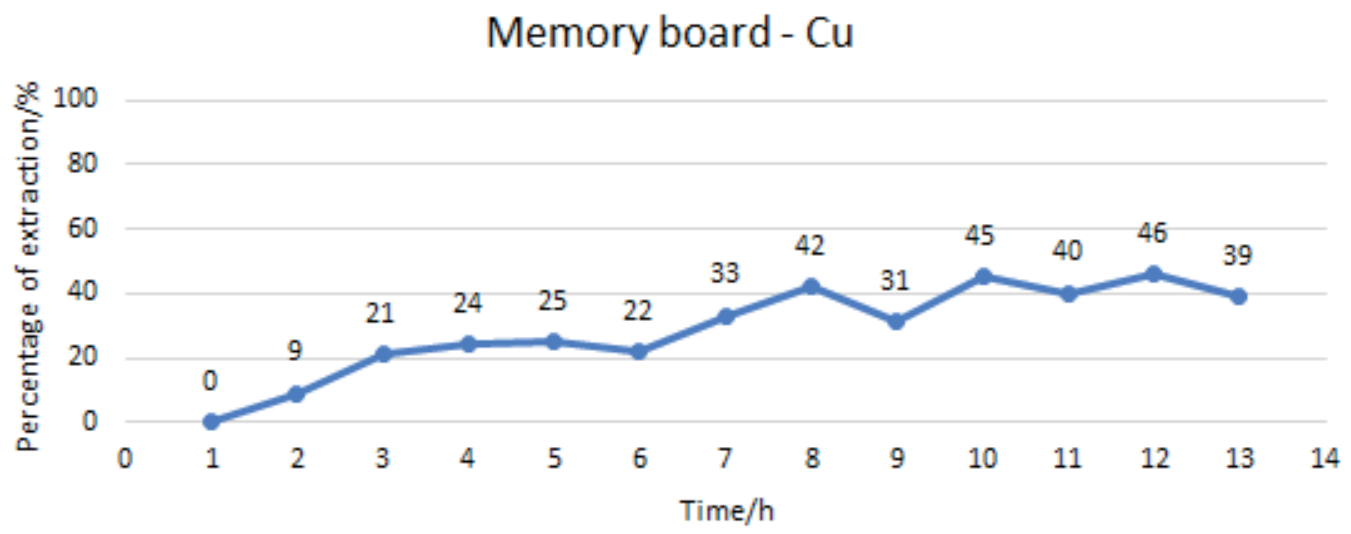

FIGURE 5: Leaching curve of Cu for the memory board with the percentage of extraction over time.

Fundação de Amparo à Pesquisa do Estado de São Paulo (FAPESP) (2012/51871-9 and 2017/17344-5).

\section{REFERENCES}

Bidini G., Fantozzi F., Bartocci P., D’Alessandro B., D’Amico M., Laranci P., Scozza E., Zagaroli M. (2015). Recovery of precious metals from scrap printed circuit boards through pyrolysis. J Anal Appl Pyrolysis., vol 111, 140-147.

Cayumil R., Khanna R., Rajarao R., Mukherjee P. S., Sahajwalla V. (2016). Concentration of precious metals during their recovery from electronic waste. Waste Mannag., vol. 57, 121-130.

Choubey, P. K., Panda, R., Jha, M. K., Lee, J., Pathak, D. D. (2015). Recovery of copper and recycling of acid from the leach liquor of discarded Printed Circuit Boards (PCBs). Sep. Purif. Technol. Vol 156, 269-275.

Cui H., Anderson C. G. (2016). Literature review of hydrometallurgical recycling of printed circuit boards (PCBs). J Adv Chem Eng., vol 6, n. 1.

Diaz L. A., Lister T. E., Parkman J. A., Clark G. G. (2015) Comprehensive process for the recovery of value and critical material from electronic waste. J Clean Prod., vol. 125, 236-244.

Ghosh B., Ghosh M. K., Parhi P., Mukherjee P. S., Mishra B. K. (2015), Wasted Printed Circuit Boards recycling: An extensive assessment of current status. J Clean Prod., vol 94, 5-19.

Gurung, M., Adhikari, B. B., Kawakita, H., Ohto, K., Inoue, K., Alam, S. (2013). Recovery of gold and silver from spent mobile phones by means of acidothiourea leaching followed by adsorption using biosorbent prepared from persimmon tannin. Hydrometallurgy, vol $133,84-93$.

Ilyas S., Ruan C., Bhatti H. N., Ghauri M. A., Anwar M. A. (2010). Column bioleaching of metals from electronic Scrap. Hydrometallurgy., vol. 101 , n. 3-4, 135-140.
Ilyas, S., Anwar, M. A., Niazi, S. B. (2007). Bioleaching of metals from electronic scrap by moderately thermophilic acidophilic bacteria. Hydrometallurgy. vol. 88, 180-188.

Kaya M. (2016). Recovery of metals and nonmetals from electronic waste by physical and chemical recycling processes. Waste Manag., vol 57, 64-90.

KITCO. (2018). Live Silver Price. Available on: http://www.kitco.com/ charts/livesilver.html.

Kumar A., Holuszko M., Espinosa D. C. R. (2017). E-waste: An overview on generation, collection, legislation and recycling practices. Resour Conserv Recy., vol. 122, 32-42.

Kumar, V., Lee, J., Jeong, J., Jha, M. K., Kim, B., Singh, R. (2015). Recycling of printed circuit boards (PCBs) to generate enriched rare metal concentrate. J. Ind. Eng. Chem., vol 21, 805-813.

LME (London Metal Exchange). 2020a. LME Copper official prices Available on: https://www.Ime.com/Metals/Non-ferrous/Copper\#tablndex $=0$.

LME (London Metal Exchange). 2020b. LME Silver. Available on: https:// www.Ime.com/Metals/Precious-metals/LME-Silver\#tablndex $=2$

Neto, I. F. F., SOUSA, C. A., Brito, M. S. C. A., Futuro, A. M, Soares, H. V. M. (2016). A simple and nearly-closed cycle process for recycling copper with high purity from end life printed circuit boards. Sep. Purif. Technol., vol 164, 19-27.

Official Journal of the European Union (2003a). Directive 2002/96/EC of the European Parliament and of the Council on waste electrical and electronic equipment (WEEE). Available on: http://eur-lex.europa.eu/legal-content/EN/TXT/?uri=celex\%3A32012L0019.

Official Journal of the European Union (2003b). Directive 2002/95/ EC of the European Parliament and of the Council of 27 January 2003 on the restriction of the use of certain hazardous substances in electrical and electronic equipment (RoHS). Available on: http://eur-lex.europa.eu/legal-content/EN/TXT/?uri=CELEX:32002L0095. 
Shokri A., Pahlevani F., Levick K., Cole I., Sahajwalla V. (2017). Synthesis of cooper-tin nanoparticles from old computer printed circuit boards. J Clean Prod., vol. 142, 2586-2592.

Silvas F. P. C., Correa M. M. J., Caldas M. P. K., Moraes V. T., Espinosa D. C. R., Tenorio J. A. S. (2015). Printed circuit board recycling: physical processing and copper extraction by selective leaching. Waste Manag., vol. 46, 503-510.
Xu Y., Li J., LiliLiu. (2016). Current status and future perspective of recycling copper by hydrometallurgy from waste printed circuit boards. Procedia Environ Sci., vol. 31, 162-170

Zhou Y., Qiu K. (2010). A new technology for recycling materials from waste printed circuit boards. J Hazard Mater., vol. 175, 823-828.

Žiūkaitè S., Ivanauskas R., Tatariants M., Denafas G. (2017). Feasibilities for hydrometallurgical recovery of precious metals from waste printed circuit boards in Lithuania. Chemija, vol. 28, 109-116. 